\title{
Editorial
}

\section{Shock and Vibration Induced by Mining Extraction}

\author{
Caiping Lu, ${ }^{1}$ Linming Dou, ${ }^{2}$ Nong Zhang, ${ }^{1}$ Marcin Aleksander Lutyński, ${ }^{3}$ and Shimin Liu ${ }^{4}$ \\ ${ }^{1}$ School of Mines, China University of Mining and Technology, Xuzhou 221116, China \\ ${ }^{2}$ State Key Laboratory of Coal Resources and Safe Mining, China University of Mining and Technology, Xuzhou 221116, China \\ ${ }^{3}$ Institute of Mining Engineering, Faculty of Mining and Geology, Silesian University of Technology, Ulica Akademicka 2, \\ 44-100 Gliwice, Poland \\ ${ }^{4}$ Department of Energy and Mineral Engineering, School of Earth and Mineral Sciences, Pennsylvania State University, State College, \\ PA 16802, USA
}

Correspondence should be addressed to Caiping Lu; cplucumt@126.com

Received 1 April 2015; Accepted 1 April 2015

Copyright (C) 2015 Caiping Lu et al. This is an open access article distributed under the Creative Commons Attribution License, which permits unrestricted use, distribution, and reproduction in any medium, provided the original work is properly cited.

With the increase of mining depth and intensity of coal resource, the rockburst and other dynamic disasters are aggravating, which seriously threaten the safety of coal mines. According to the convincing statistics, only 32 coal mines belonged to rockburst mines until 1985 in China; unfortunately, by the end of 2011, nearly 142 coal mines were classified as rockburst tendency. Simultaneously, the mining depth of about 50 coal mines reaches or surpasses $1000 \mathrm{~m}$. In the period of 2006-2013, 35 fatal rockbursts occurred, which cruelly killed over 300 workers and caused a thousand of injures. In despite of lack of accurate data about rockburst in other countries, we can infer that the rockburst may be a ubiquitous dynamic disaster in deep coal mines in the world.

It is well known that the mining-induced shock or vibration can easily trigger strong tremor (even rockburst disaster). Therefore, it is very urgent to essentially understand the mining-induced shock and vibration waves in coal mines.

This special issue is dedicated to fundamental understanding of mining-induced shock and vibration waves mainly concentrated on mechanical principles, propagation and attenuation laws, monitoring and warning methods, and prevention of catastrophic shock. The special issue is mainly divided into 3 aspects that are the mechanism of rockburst, early warning based on microseism (MS) and electromagnetic emission (EME) methods, and prevention measures, respectively. The rest mainly discuss rock mechanics and some relevant rules, underground pressure behaviors, and innovative supporting technologies of roadway in deep coal mines. By rigorous review and negotiation, two highlights are presented which are the numerical simulation method of roadway rockburst process recurrence and the comprehensive warning method of rockburst by MS and EME and acoustic emission (AE).

Rockburst in coal mines is a worldwide conundrum poorly understood; the prediction indexes are confusing and exasperating. In particular, its prevention is yet not effectively resolved. The satisfactory solution compulsorily requires the worldwide efforts and cooperation in mining and rock mechanics community.

Caiping $\mathrm{Lu}$

Linming Dou Nong Zhang

Marcin Aleksander Lutyński Shimin Liu 

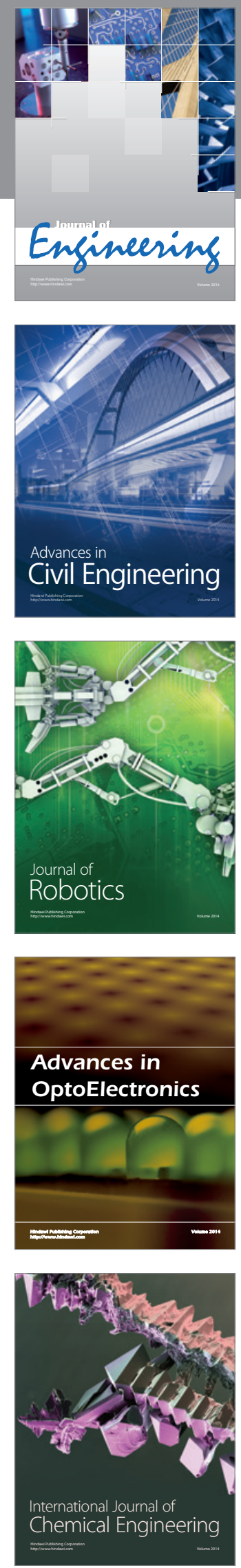

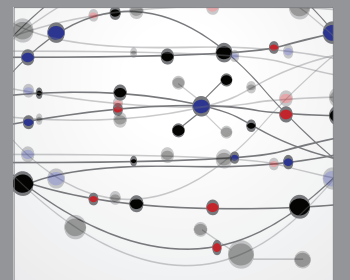

The Scientific World Journal
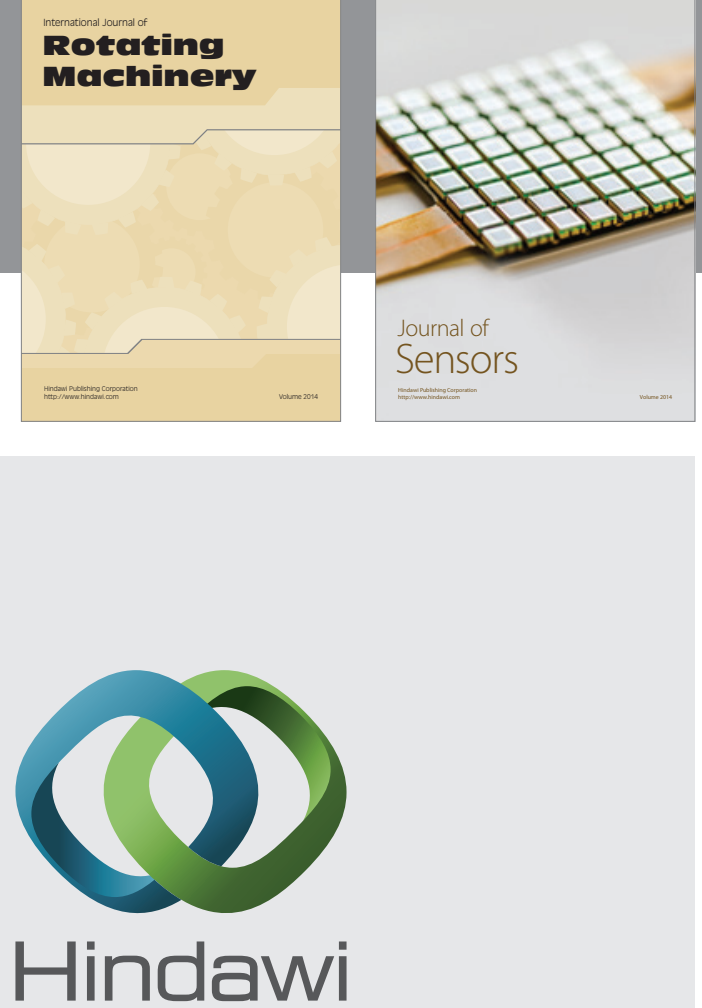

Submit your manuscripts at http://www.hindawi.com
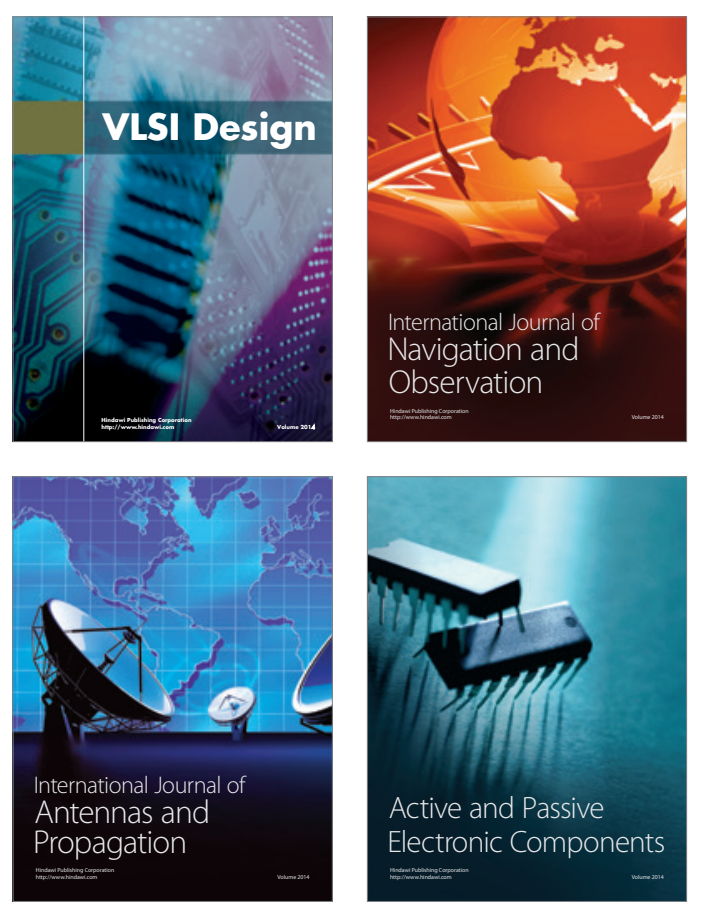
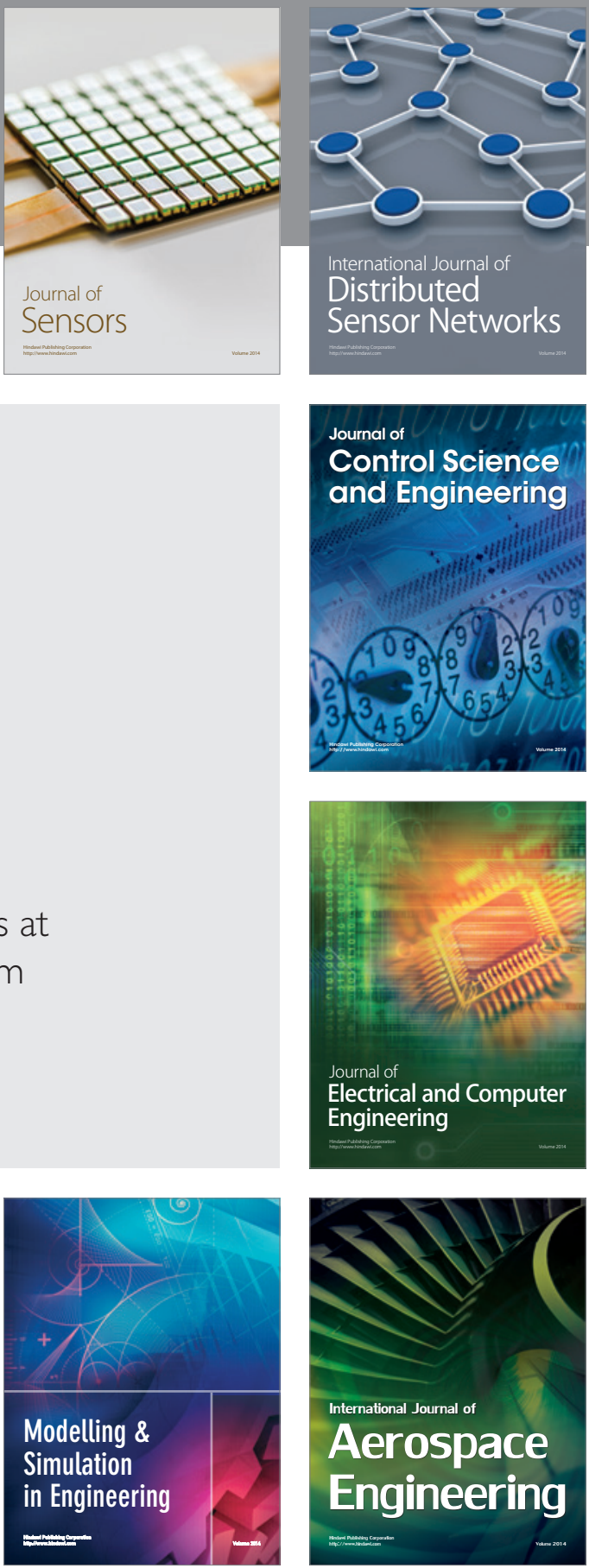

Journal of

Control Science

and Engineering
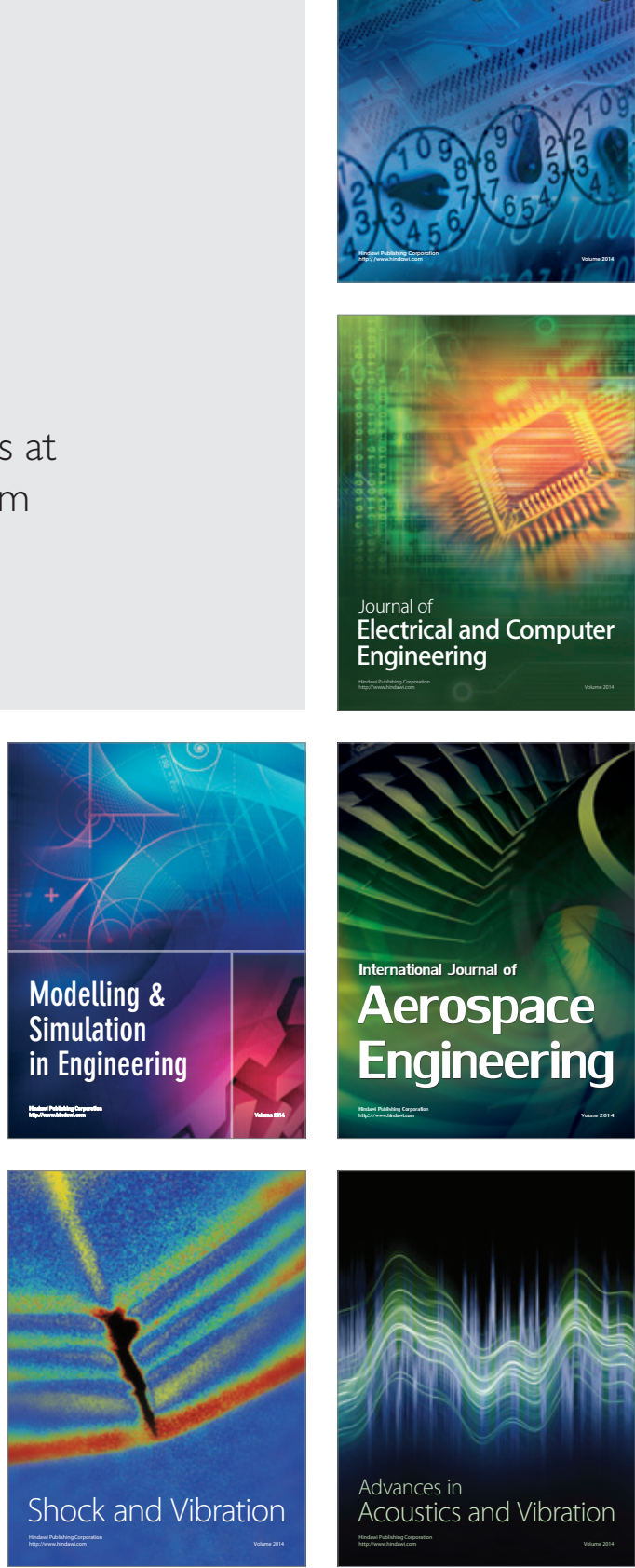